\title{
Examining the impact of knowledge elements on the achievement of project benefits in project-oriented organizations
}

\author{
Nevena Mihajlovic \\ EDUCONS University, Faculty of Project and Innovation \\ Management, Belgrade \\ Surdulica, Serbia \\ nevenamihajlovic87@gmail.com
}

\author{
Marina Apostolovska \\ Union of Engineers and Technicians of Serbia, Belgrade \\ Surdulica, Serbia \\ marinaapostolovska@yahoo.com
}

\begin{abstract}
The research presented in the paper aims to show how knowledge at work influences the achievement of project benefits in organizations in southern Serbia. The subject of this research paper is to examine the elements of knowledge management in a project in southern Serbia. The research aims to ensure the transfer and dissemination of knowledge throughout the organization, to provide the knowledge needed to make the best decisions and business processes, to encourage and ensure the quality development of new knowledge, to support and influence the acquisition of knowledge from other sources and to develop the ability to successfully implementation and use, ensuring that new knowledge is conveyed to employees who need it. The purpose is to increase the ability to create the value of an organization through the effective use of knowledge. The task of this type of management is to formulate and implement strategies for developing, acquiring and applying knowledge, improving business processes through knowledge development, monitoring and estimating profits through improved application of knowledge; monitoring and evaluation of management activities in relation to knowledge, its development and application. The paper presents a research and scientific examination of theoretical assumptions and their interconnections, ie the assumption that knowledge management tools positively affect the project benefit; knowledge storage positively affects the project benefit; knowledge transfer positively influences the project benefit. The survey was conducted in the field through surveys. 244 questionnaires were filled in 14 organizations. After checking the validity of the questionnaire, the data were statistically processed in the SPSS and LISREL programs.
\end{abstract}

Keywords-benefit, knowledge management, knowledge storage, knowledge transfer, application of knowledge.

\section{INTRODUCTION}

Knowledge management is a specialized management discipline dealing with the acquisition, creation, transfer and application of knowledge, to improve efficiency and competitiveness, and to bring about change and innovation and to achieve the necessary competitive advantage and better position in the market [1]. Starting a knowledge management project involves motivation and achievement of a competitive advantage.
An example cited by Gene Bellinger as an explanation for the application of knowledge management in organizations is: "In order for the organization to conduct the knowledge management on a project it needs to be available: data, information, knowledge, wisdom." [2]

The knowledge management process is the creation of an up-to-date knowledge base, which is constantly being upgraded and accessible to all decision makers, to improve the decision-making process and improve business efficiency, through the creation and introduction of innovation and change. Knowledge today is a key element of a profitable business [1].

With the increasing use of project management in organizations, with us leads to the need of researching and analyzing what is new in project management, which are new problems and challenges [3]. Since this is influenced by foreign companies and financial institutions, and the need for project managers has increased, we need to explore the application of project management in Serbia. There are a number of national project management associations in the world that are constantly engaged in upgrading knowledge and implementing project management. Seminars are held, regional conferences on project management, however, regarding the state of Serbia It is completely different, there is no need for project management. Several educational and other project management organizations, strong project units in the administration, need to be formed. $[3,4]$.

\section{RESEARCH HYPOTHESES}

In this research work, three hypotheses $(\mathrm{H} 1, \mathrm{H} 2$, H3) are formulated in the following way:

Hypothesis H1: The application of knowledge management tools in project-oriented companies has a positive impact on the achievement of project benefits.

Hypothesis H2: The application of knowledge management tools in project-oriented companies has a positive impact on the achievement of project benefits. 
Hypothesis H3: The application of knowledge transfer in project-oriented companies has a positive impact on the achievement of project benefits.

\section{A. Knowledge management tools on the project and benefits}

Knowledge management is such a circular system that allows the organization to effectively fulfill its goals thanks to the ability to convert explicit knowledge into habits, to better plan and implement knowledge.

Application of tools and techniques of knowledge management facilitates the flow and control of information on the project, and also supports the process of distributing knowledge among the members of the project teams. Internet, search software, email, data usage techniques, databases and many other products of modern information technology are elements of knowledge management tools both in projects and within the organization.

Their application makes more efficient processes of integration, distribution and knowledge management. Application of knowledge management tools and techniques helps managers and project teams, both in solving operational tasks, as well as in the learning process, and thus increases the chances of success of the project $[5,6 \ldots 10]$.

The results of the processed data, collected by employee surveys, showed that the items within the used questionnaire on knowledge management tools have a positive impact on the project benefit.

\section{B. Knowledge storage and project benefit}

Projects are temporary organizations, designed to bring some benefits to the home organization and interest groups through complex process of solving tasks and problems. As such, projects should be an effective way of combining knowledge and learning, which contributes to the increase in value of investments $[1,11,12]$. However, the essence of the project is such that the priority is focused more on time, product and service, rather than on activities of gathering, storing and redistributing knowledge. Therefore, there is a great risk that knowledge accumulated during project realization will irretrievably be lost after its completion and that the project oriented organization limits both the growth of its knowledge and its overall development. How will this not be achieved and how the acquired knowledge will be reused and improved, it is necessary to adequately document and store them in the databases, from where they can be re-accessed and from where they can be distributed to the employees within the projects, in order to more efficiently realize the project goals.

Knowledge retention is a significant part or subset of the knowledge management process, which aims to, in addition to classifying and archiving available knowledge from different users, including managers at different levels, experts in various specialties, and researchers and scientists from different fields. The validity of a defined and realized way of storing knowledge depends on how efficient the transfer and use of available knowledge will be and how quickly this knowledge will be supplemented [1].

The results of the processed data, collected by employee surveys, showed that the items within the used questionnaire on the storage of knowledge have a positive impact on the project benefit.

\section{Knowledge transfer and project benefit}

Relations and interactions between the knowledge economy and human resources management must be viewed in the light of the many changes that occur in the business environment. Developing the knowledge economy and strengthening the relationship between organization and individuals, provides solutions to unpredictable events that the organization has found. The role of management is of great importance, an efficient manager should support the collection and sharing of knowledge by encouraging individuals to use their skills in knowledge.

Choi argue that knowledge sharing can lead to better team performance due to improved decision making and coordination [13]. Stasser and Titus found that accumulated knowledge sharing leads to a greater understanding of the unsolved issues and the existing knowledge between team members, which contributes to improved decisions. Given experience in sharing knowledge, team members are able to understand tiny cues from others and fix errors [14].

Knowledge sharing improves performance by leading to innovative solutions to business problems [15]. Tesch states that development is an intensive process that requires knowledge, the integration of the business domain of knowledge and the development of technical knowledge for success [16].

The results of the data processed, collected through a survey of employees in organizations, showed that items within the used knowledge transfer questionnaire had a positive effect on the project benefit.

\section{DATA COLLECTION}

The method used in this research is the survey method. The survey was conducted in the territory of southern Serbia. The organizations surveyed were selected at random. Respondents completed the questionnaire by completing it, all completed questionnaires were valid ( 244 pieces)

The questionnaire used in the survey contains 18 questions, which are divided into 4 groups, namely: AUZ - Knowledge Management Tools; SZ - Storage of knowledge; RZ - Knowledge transfer; PB - Project benefit.

The questionnaire also contains 9 control questions: Q1 - Employer gender; Q2 - Age of employer; Q3 - Years spent in organization; Q4 School degree (elementary - secondary - upper - high - master / doctorate); Q5 - Project position (manager - 
worker - support staff); Q6 - Number of employees in the organization; Q7 - Age of the organization (years); Q8 - Ownership structure of the organization; Q9 - Type of investment project.

The five-step Likert scale was used to evaluate the answers given in the questionnaire, with the scale values having the following meaning: 1 - I disagree at all; 2 - I disagree; 3 - I have no opinion; 4 - I agree; 5 - I totally agree.

\section{RESEARCH MODEL}

Based on the facts presented, hypotheses formed, a conceptual model of research was drawn up, which is shown in Figure 1:

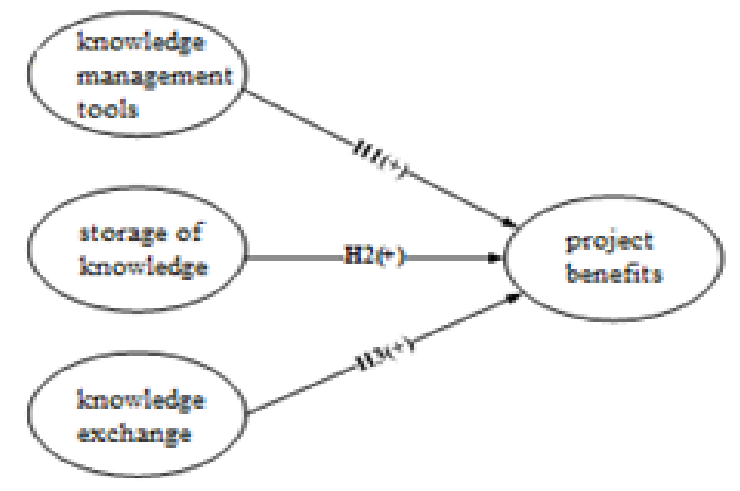

Figure 1: Research model

The labels used for the specific question groups are: AUZ - Knowledge Management Tools; SZ Storage of knowledge; RZ - Knowledge transfer; PB Project benefit.

\section{A. Demographic statistics}

Out of 244 respondents, 177 respondents were male, which is $72.5 \%$, while women were 67 and $27.5 \%$, respectively. The largest number of respondents was between 46 and 55 years of age, or $26.6 \%$, while the smallest number of respondents was more than 56 years old.. In terms of years spent in the organization, we mostly have workers who have spent up to 5 years working in the organization, which is $45.1 \%$ in percentage. Based on the level of education, we have the highest number of respondents with secondary education, which is $80.3 \%$ in percentage. We had the most working-class respondents in the project, which is $92.6 \%$. The data show that when asked about the size of the organization, the most represented are those with 51-250 employees and that the organizations themselves are old because the largest number of respondents answered that the chronological age of their organizations is $\geq 31$ years. Based on the obtained data, it can be concluded that in the south of Serbia, domestic ownership prevails, ie 214 respondents out of 244 respondents answered that the ownership structure is domestic. When it comes to the type of investment project in which the surveyed companies operate, 141 of them are in the equipment sector, 88 in infrastructure facilities, 12 in consulting organizations, 3 in construction facilities.

\section{B. Descriptive variable statistics}

Data descriptive statistics for groups of questions tools of knowledge management; storage of knowledge; knowledge transfering and project benefit are shown in table $\mathrm{T} 1$. The mean value, median, modus, standard deviation, and variance were made.

TABLE I. COLLECTIVE DESCRIPTIVE STATISTICS OF VARIABLES

\begin{tabular}{|l|l|l|l|l|l|}
\hline Variable & $\begin{array}{l}\text { Middle } \\
\text { value }\end{array}$ & Mediana & Modus & $\begin{array}{l}\text { Standard } \\
\text { Deviation }\end{array}$ & Variance \\
\hline AUZ1 & 4,2664 & 4,0000 & 5,00 & 0,76896 & 0,591 \\
AUZ2 & 3,9795 & 4,0000 & 5,00 & 0,88168 & 0,777 \\
AUZ3 & 3,8402 & 4,0000 & 3,00 & 0,93132 & 0,867 \\
AUZ4 & 3,3156 & 3,0000 & 3,00 & 1,01977 & 1,040 \\
AUZ5 & 3,5861 & 3,0000 & 3,00 & 0,90539 & 0,820 \\
\hline SZ1 & 4,2336 & 4,0000 & 4,00 & 0,65321 & 0,427 \\
SZ2 & 4,1393 & 4,0000 & 4,00 & 0,70641 & 0,499 \\
SZ3 & 3,8484 & 4,0000 & 4,00 & 0,78930 & 0,623 \\
SZ4 & 3,8402 & 4,0000 & 4,00 & 0,79289 & 0,629 \\
SZ5 & 4,0287 & 4,0000 & 4,00 & 0,75031 & 0,563 \\
\hline RZ1 & 4,3975 & 4,5000 & 5,00 & 0,68625 & 0,471 \\
RZ2 & 3,8033 & 4,0000 & 4,00 & 0,76593 & 0,587 \\
RZ3 & 3,6107 & 3,0000 & 3,00 & 0,81653 & 0,667 \\
RZ4 & 3,5984 & 3,0000 & 3,00 & 0,80287 & 0,645 \\
RZ5 & 4,1107 & 4,0000 & 4,00 & 0,73146 & 0,535 \\
\hline PB7 & 4,3525 & 4,0000 & 4,00 & 0,64689 & 0,418 \\
PB8 & 3,7992 & 4,0000 & 3,00 & 0,76755 & 0,589 \\
PB9 & 4,4385 & 4,5000 & 5,00 & 0,60884 & 0,371 \\
\hline
\end{tabular}

\section{Checking the reliability of the scale}

To verify the reliability of the scale, the Kronbach alpha coefficient is used, which is the most commonly used coefficient for determining the degree of similarity of the items. Ideally, the Kronbach alpha coefficient should be greater than 0.7 , while values up to 0.5 would be considered unacceptable [17]. Table T2 shows the measurement of reliability of the scale for questionnaire questions from the questionnaire, as well as for the entire model.

TABLE II KRONBACH'S ALPHA COEFFICIENT FOR THE GOUP OF QUESTIONS

\begin{tabular}{|l|l|}
\hline A group o0f questions & $\begin{array}{l}\text { Kronbach coefficient } \\
\text { alpha }\end{array}$ \\
\hline AUZ & 0.884 \\
\hline SZ & 0.940 \\
\hline RZ & 0.905 \\
\hline PB & 0.756 \\
\hline Model & 0.954 \\
\hline
\end{tabular}

Source: Authors' Works (SPSS)

On the basis of the data obtained from the table T2 mentioned above, the following conclusions about the results obtained for the group of questions can be made: AUZ, SZ, RZ Kronbach's coefficient of alpha is above the need and the desired value, while the results for the $\mathrm{PB}$ issue group are slightly above the recommended value. The Kronbach alpha coefficient was calculated for all 18, the issues that were the subject of research, and the value was obtained from $\alpha \geq 0.954$, which is above the recommended value. Finally, it can be observed from the Cronbach's alpha coefficient that the measurement scale is reliable and that there is agreement of the sample scale. 


\section{Measures of fitting}

The goodness-of-fit measures model were determined based on the CFA analysis. The values of some of the parameters are shown in the Table T3.

TABLE III

Model fit measures

\begin{tabular}{|l|l|l|}
\hline Goodness of Fit measure & $\begin{array}{l}\text { Model } \\
\text { value }\end{array}$ & $\begin{array}{l}\text { Recommended } \\
\text { values }\end{array}$ \\
\hline Chi-Square $\left(\chi^{2}\right)$ & 1084 & - \\
\hline Degree of freedom $($ d.f. $)$ & 429 & - \\
\hline Normed Chi-Square $\left(\chi^{2} /\right.$ d.f. $)$ & 2.52 & $<3.0$ \\
\hline RMSEA & 0.10 & $\leq 0.10$ \\
\hline GFI & 0.83 & $>0.8$ \\
\hline AGFI & 0.72 & $>0.9$ \\
\hline CFI & 0.92 & $>0.9$ \\
\hline IFI & 0.92 & $>0.9$ \\
\hline NFI & 0.91 & $>0.9$ \\
\hline NNFI & 0.90 & $>0.9$ \\
\hline RFI & 0.89 & $>0.9$ \\
\hline & \multicolumn{2}{|l|}{ Source: Authors' Works (SPSS) } \\
\hline
\end{tabular}

The values of the obtained indicators are analyzed to determine whether the proposed model fits the input data satisfactorily. Indicators considered: RMSEA and GFI have the following meaning:

-RMSEA indicator expresses the error of approximation and its value is lower this model better fits the initial data. An acceptable model is characterized by the values of this indicator that are within $\leq 0.10$. From the results we can see that the RMSEA indicator has a value of 0.10 which represents a satisfactory value.

- GFI moves between 0 and 1. Acceptable values are above 0.8.This indicator $(\mathrm{GFI}=0.83)$ can be considered very good because the value for the model is above the required value of 0.8 and we can conclude that the model indicates good data matching.

Also, FIT analysis shows for indicators CFI = 0.92 ; IFI $=0.92$ and NFI $=0.91$ to be above the recommended limit value.

The value for the model is $\chi^{2} /$ d.f. $=1084 / 429=$ 2.52 is less than 3.0 which represents a satisfactory value. The data in Table T3 show the authenticity of the test except for RFI value $=0.89$, which is below the limit of the recommended value, but this does not change the reliability of the performed testing.

\section{E. Correlation analysis}

The implementation of the correlation analysis is carried out in the software program LISREL and involves a procedure of 8 steps. The type of connections that exist between the observed phenomena, ie the existence of direct connections, is checked. The results are shown in Table T4.

TABLE IV. CORRELATION
VARIABLES
\begin{tabular}{|l|l|l|l|l|}
\hline & AUZ & SZ & RZ & PB \\
\hline AUZ & 1 & & & \\
\hline SZ & $0.50^{*}$ & 1 & & \\
\hline RZ & $0.48^{*}$ & $0.81^{*}$ & 1 & \\
\hline PB & $0.41^{*}$ & $0.75^{*}$ & $0.72^{*}$ & 1 \\
\hline
\end{tabular}

Note: level of statistical significance $* \mathrm{p}<0.05 ; * * \mathrm{p}<0.01$

Source: Authorship (LISREL)
The results obtained indicate that the relationships between the variables have a positive value. It can therefore be concluded that there is a direct correlation between all groups of questions AUZ, SZ, RZ and PB. The level of statistical significance of correlation links is indicated by asterisks, and explained in the note below Table T4.

\section{DISCUSSION OF RESULTS}

LISREL software tested the statistical hypotheses of a survey conducted in southern Serbia. The goal of regression is to determine the nature of the relationship, or the form of dependence between the observed phenomena.

We have set the following hypotheses:

H1: The application of knowledge management tools in project-oriented companies has a positive impact on the achievement of project benefits.

$\mathrm{H} 2$ : The application of knowledge management tools in project-oriented companies has a positive impact on the achievement of project benefits.

H3: The application of knowledge exchange in project-oriented companies has a positive impact on the achievement of project benefits.

The results of the research model analysis are shown in Figure 2. Above the arrows are shown the values of the coefficient of regression ( $\beta$ coefficients of the path). Data in brackets represent t-test values. The statistical significance level is marked with asterisks.

On the basis of the obtained results of the path of the analysis, it can be noticed that all the coefficients of the path (regression) have a positive value, which means that all three hypotheses have been confirmed since for the hypothesis H1 $\beta=0$. 28, for the hypothesis $\mathrm{H} 2 \beta=0.23$ and for the hypothesis $\mathrm{H} 3 \beta=$ 0.04.

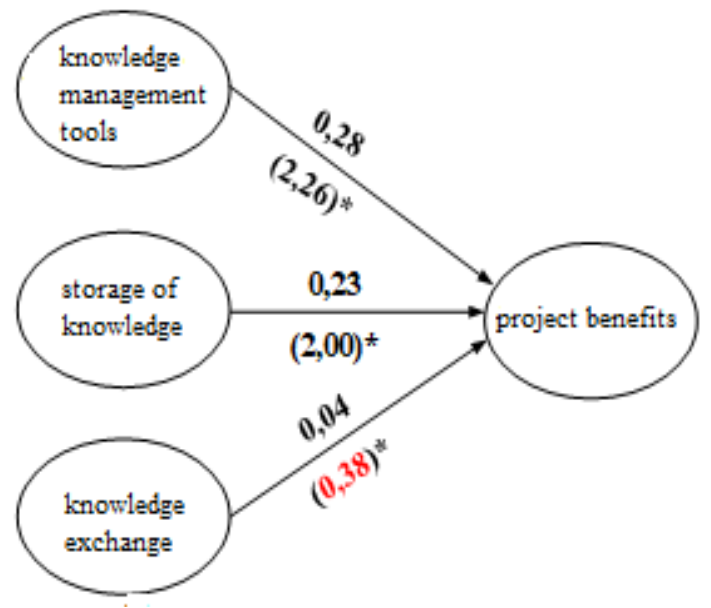

Figure 2. Research model

In order to make a decision on the acceptance of the hypothesis an appropriate t-test was made and in this way the statistical significance of the obtained results was verified. From the obtained results, we 
conclude that hypothesis $\mathrm{H} 3$ cannot be accepted because the coefficients are below the recommended value of 1.96. The hypotheses $\mathrm{H} 1$ and $\mathrm{H} 2$ are accepted because their value is $\mathrm{H} 1=2.26 ; \mathrm{H} 2=2.00$ greater than the recommended value 1.96 , with a statistical significance of $\mathrm{p}=0.10$.

The figure also shows the values of the coefficient of determination (R2). Determination coefficients are determined only for dependent groups of questions, in our case it is a group of PB questions. The coefficient of determining is the percentage by which AUZ, SZ and $\mathrm{RZ}$ can explain the impact on $\mathrm{PB}$, and in this case it is $27 \%$.

$\mathrm{H} 3$ hypothesis is not acceptable and statistically significant because among the engaged members of the project there is no exchange of knowledge. The survey shows that the most significant factors that hinder or reduce the ability to share knowledge are: lack of time to share knowledge and time needed to identify colleagues who possess specific knowledge; the feeling of fear that sharing knowledge with others can endanger job security; differences in level of experience; differences in education level; lack of trust among colleagues; lack of confidence in the accuracy and credibility of knowledge; lack of visible recognition and rewards, so that employees are motivated to share their knowledge; lack of training to use and learn about new technologies.

The ways to improve the knowledge sharing practice in organizations based on these results are: the introduction of time and space for sharing and transferring knowledge; additional education of employees; build trust through dialogue; introduction and improvement of human resources management with a view to the desired exchange of knowledge; introduction of rewards for knowledge exchange; introduction and organization of seminars and professional training of employees.

The literature states that the success of an organization depends primarily on the exchange of knowledge between employees, research shows that this is really necessary. This research can be used for further research that would contribute to knowledge dissemination in knowledge management in organizations.

\section{CONCLUSION}

Knowledge management is the process of systematically connecting people and people with knowledge and information to effectively work and create new knowledge. Knowledge management leads to error reduction, faster problem resolution, improvement of relations with employees and improvement of products and services. Knowledge management helps the organization gain insights and understanding based on its own experience.

The research conducted on the territory of southern Serbia analyzed the effects of knowledge elements on the achievement of project benefits in project-oriented organizations. The results showed that knowledge exchange almost does not exist between the knowledge management team leader and the organization's employees. The main undertaking for each organization should be the formation of a knowledge management system, as this would ensure the involvement of employees in the realization of the strategic goals of the organization. In order for this venture to be successful, it is necessary that the program covers the entire organization. Also, the team leader needs to communicate well with the responsible manager and employees for better knowledge exchange.

Knowledge is transferred from the place of knowledge storage to certain knowledge bases. Individuals possessing knowledge, either explicitly or implicitly, are very difficult to convey to others. They prefer to store the knowledge they own, because they consider that if they transfer it and share it with other workers, then the significance of that knowledge is reduced. They consider what everyone knows lose a partial value, and therefore decide to hide their knowledge.

The greatest number of barriers to successful knowledge management actually relate to barriers to knowledge sharing with others.

Finally, we can conclude that the application of tools and techniques of knowledge management facilitates the flow and control of information on the project, knowledge transfering improves performance, leading to an innovative solution to business problems.

\section{REFERENCES}

[1] P. Jovanović, 'UUpravljanje znanjem', Zuhra, Beograd, 2014.

[2] G. Belinger, 'Knowledge Management - Emerging Perspectives", Systems thinking, 2014.

[3] P. Jovanović, 'Upravljanje projektima - Autorizovana predavanja", VŠPM, Beograd, 2015.

[4] P. Jovanović, 'Projektni menadžment u Srbiji - Uspesi i mogućnosti', XV Internacionalni simpozijum iz projektnog menadžmenta, YUPMA 2011, Zlatibor, 2011.

[5] J. Whyte and S. Lobo, 'Coordination and control in project based work: digital objects and infrastructures for delivery', Construction Management and Economics, 28, pp. 557-567, 2010.

[6] E. D. Adamides and N. Karacapilidis, ',Information technology support for the knowledge and social processes of innovation management', Technovation, 26, 50-59, 2006.

[7] M. R. Halfawy, "Municipal information models and federated software architecture for implementing integrated infrastructure management environments", Automation in Construction, 19, 433-446, 2010

[8] Z. Chen, and Z. A. Liu, '’A study of Knowledge Management in Construction Project Management', Energy Procedia, 11, 1039-1044, 2011.

[9] L. R. Yang, J. H. Chen and H. W. Wang, 'A Assessing impacts of information technology on project success through knowledge management practice", Automation in Construction, 2012.

[10] J. S. Cholu and J. G. Yang, 'Evolutionary optimization of model specification searches between project management knowledge and construction engineering performance', Expert Systems with Applications, 2014.

[11] B. Bergeron, 'Essentials of Knowledge Management', John Wiley \& Sons, New Jersey, 2003.

[12] P. Gottschalk, "Strategic Knowledge Management Technology, Idea Group Publishing, 2004.

[13] S. Y. Choi, H. Lee and Y. Yoo, 'The impact of information technology and transactive memory systems on knowledge 
sharing, application and team performance: a field study", MIS Quarterly 34, 2004

[14] G. Stasser and W. Titus, '’Pooling of unshared information in group decision making: biased information sampling during discussion', Journal of Personality and Social Psychology 48, 1985

[15] M.T. Hansen, Knowledge networks: explaining effective knowledge sharing in multiunit companies. Organization Science 13, 18, 2002.
[16] D. Tesch, M. G. Sobol, G. Klein and J.J. Jiang, '’User and developer common knowledge: effect on the success of information system development projects", International Journal of Project Management 2, 2009.

[1] A. Van de Ven and D. Ferry, 'Measuring and assessingorganizations', Wiley, New York, 1979. 